\title{
Students’ Perceptions of Learning Mathematics with Cellular Phones and Applets
}

\author{
doi:10.3991/ijet.v4i1.686 \\ W. Daher \\ Al-Qasemi College of Education, Baka, Israel
}

\begin{abstract}
This paper describes the perceptions of middle school students regarding learning mathematics with cellular phones and web applets, their perceptions regarding the differences between these two electronic devices and their preferences regarding using the devices in learning mathematics. To analyze these perceptions I used the grounded theory approach which involves: open coding, axial coding, and selective coding, where the unit of analysis was the sentence in each of the interviews. The research findings imply that the participants perceived different aspects of both of the electronic devices: the availability of the device, the collaborative aspect, the communication aspect, the size of the device, and the usability of the device. These aspects influenced the participants' decisions when, where and how to use each of the devices for the learning of mathematics. More participants preferred the cellular phone over the applet primarily for its small size which makes easy its portability as well as for its communication facilities.
\end{abstract}

Index Terms-Mobile leaning, cellular phones, learning with applets, learning mathematics, perceptions of students.

\section{INTRODUCTION}

\section{A. The Research Goal}

The research goal was to find how middle school students respond to learning mathematics using cellular phones, what there perceptions are of this learning and of the differences between learning mathematics with cellular phones and learning mathematics with applets.

\section{B. Rationale}

In a conference in 2006, the chairman of Motorola admitted that in the mid-1980s the mobile phone industry estimated that by the year 2000, there would be a market for about 900,000 mobile phones worldwide. When we reached the mentioned year, 900,000 phones were being sold every 19 hours [1]. We wetness an acceleration in this rate, and the research firm Informa Telecoms and Media predicted that in the year 2007 the total number of subscribers will reach over three billions for the first time, almost half of the world's population (according to [1]). Actually, by the year 2007 the statistics of the International Telecommunication Union reported that 47 persons of each 100 worldwide own mobile phone. These numbers will continue to increase especially with the embedding of new technologies in these phones. Most of the mobile phones today come with: MP3 player, high resolution camera and a variety of complex games. As technology continues to get smaller, memory cheaper and software more sophisticated, more and more features will be packed into these digital Swiss army knives [1]. Even though, some people still think of their mobile phones as just a chatting device, we see that these phones become really our new small PC [1]. This increase in the owners of mobile phones is worldwide and isn't restricted to industrialized countries, though the increase is not uniform.

Despite the facts mentioned above, the use of mobile technology in education is rather new [2] and is still in its infancy [3]. This is especially true in the case of cellular phones and particularly in the case of mathematics, but this technology is starting to be the setting, primarily in universities. Ref. [4] says that opportunities and challenges are emerging for learners from the increasing availability of mobile and wireless devices. It seems time for cellular phones to go to the mathematics classroom in middle schools, for their various potentialities to the learning of mathematics.

How would middle school students perceive the learning of mathematics with this new device and how would they perceive the difference between it and working with web applets? Knowing students' perceptions of learning with cellular phones and web applets would certainly help teachers prepare appropriate activities for each of the devices and help designers design new generations of the devices.

\section{Background}

Electronic media and tools are spreading in educational contexts, among which is mathematics teaching and learning. Applets are used in mathematics education for almost a decade now, where educational sites use them to offer tools with which users are expected to work in order to learn new mathematical topics or solve mathematical tasks and problems. Cellular phones are rather new as devices that students learn mathematics with. Cellular phones use educational software programs called midlets which are similar, in their interface and some of their functions, to applets, but differ from applets in that they enable users to communicate their working screen to other users. Researchers have investigated the use of applets in the mathematics classroom (for example [5], [6], [7]), but few researches have been done regarding the use of cellular phones in mathematics education (some are [8], [9]), though some research was done on using cellular phones in education (for example [10], [11]).

Ref. [12] describes some advantages of mobile learning: mobile devices can engage individuals in learning at times they would have been doing something else; mobile devices motivate learners because of their attractiveness; they enable communication from 
anywhere; formal learning can suit existing patterns of self publishing and online participation; mobile learning enables multitasking. Ref. [13] describes the following disadvantages of mobile devices that affect mobile learning: small screen size, limited memory size, small keyboards, limited battery life, high costs, possibility for mobile devices to be misplaced or stolen, and difficulty to use mobile devices in noisy environments. Ref. [14] describes some advantages and disadvantages of web applets: They are freely and easily found on the web and offer students visualization and interactivity, but they are not accompanied with detailed documentation and activities to guide students' use and have problems regarding their portability.

It's the goal of this research, to find how middle school students perceive cellular phone and web applets learning, their advantages and disadvantages, and how these perceptions influence the students' attitudes, their future actions and methods of learning mathematics using cellular phones or web applets.

\section{RESEARCh DESIGN}

\section{A. The Learning Setting}

The researcher met the participants face to face to introduce them to learning mathematics with cellular phones and learning mathematics with web applets. He accompanied the students' learning of mathematical topics with cellular phones and web applets. At the end of the project the researcher interviewed the participants inquiring about their perceptions of learning mathematics with the devices.

\section{B. Participantss}

The participants were fifteen ninth grade students from three middle schools in the same area; nine males and six females, who volunteered to study mathematics outside their school using cellular phones and web applets. All of these students were considered by their math teachers to be strong students in math, but none of them had experienced learning mathematics using web applets or cellular phones.

\section{Learning Tasks}

The learning tasks given to the students participating in the research included mathematical exercises and word problems which were similar to exercises and word problems that were part of their usual math curriculum.

\section{The Mathematical Software}

The participants worked with cellular phone software (midlets) which they downloaded from 'Math4Mobile' site with the help of each other and the help of the researcher. They used three methods to do that: (1) going to the Math4Mobile site directly from their phones and downloading the midlets (2) downloading the midlets to their computers and then using the phone's connectivity software and a cable or an infra-red link to copy the downloaded midlets to their phones (3) sending the downloaded midlet, using the Bluetooth to other students The midlets support the learning of algebra and geometry. In order to perform the activities assigned to them, the students needed to use the algebraic midlets and various tools and technologies embedded in their mobile phones.
The mostly used midlet by the participants was "Graph2Go" which enabled the students to draw graphs of functions and to transform these functions. Another midlet which was used by the participants is "Fit2Go" which enables the user to draw specified points and then to fit a linear or a quadratic function for them.

The participants used the web applets from the 'Visual Math: Functions' site. The web applets which the students used in the experiment dealt with linear and quadratic functions. The mostly used applet by the participant was "Representation of Functions" which does nearly the same as the midlet "Graph2Go". They also used the applet "Representation of Points" which is quite similar to the midlet "Fit2Go", but with the applet the user tries several functions to find out which one fits the points.

\section{E. The cellular phones}

The minimum requirements for the phones which enable working with the midlets were: (1) Java Enabled (J2ME) Phone - Profile/MIDP-2.0 Configuration/CLDC1.1 (2) Screen Resolution: 128 x 96. The cellular phones used by the participants were $3^{\text {rd }}$ generation phones that had $105 \times 46 \times 15 \mathrm{~mm}$ or similar screen's dimensions like $99 \times 53 \times 21 \mathrm{~mm}$. The internal memory of the phones varied from $35 \mathrm{MB}$ to $160 \mathrm{MB}$. The screen's colors varied from $256 \mathrm{~K}$ colors to $16 \mathrm{M}$ colors.

\section{F. Interviews}

Each of the participants was interviewed for 45 minutes about her or his perceptions of learning mathematics using cellular phones and web applets, and the differences between learning mathematics with cellular phones and learning mathematics with web applets. The interviews were semi-structured. All the interviews were tape recorded and afterwards transcribed verbatim.

The students participating in the research were asked about the following issues regarding their learning mathematics with cellular phones and with web applets: (1) whether and what they think they benefited from learning mathematics using cellular phones or web applets, (2) when and where they prefer to use cellular phones or web applets to learn mathematics, (3) whether and why they would use cellular phones or applets in learning mathematics in the future, (4) the differences between using cellular phones and using web applets in learning mathematics, and (5) which device they prefer to use when coming to learn mathematics.

\section{G. Data Analysis}

The analysis followed the grounded theory approach [15] which involves: open coding, axial coding, and selective coding, where the unit of analysis was the sentence in each of the interviews.

\section{FINDINGS}

The students' perceptions of learning mathematics using cellular phones or web applets are described below. This will be done for each of the issues that were mentioned above and which were raised in the interviews with the participants. 


\section{A. Benefits of using cellular phones and web applets in learning mathematics}

The participants highlighted the following aspects as characterizing the benefits of learning mathematics with cellular phones and applets: (1) visualizing mathematical problems, (2) solving mathematical problems in short time, (3) solving mathematical problems without much effort, (4) solving precisely, (5) making students participate more actively in their learning, and (6) ensuring the correctness of paper and pencil solutions.

\section{B. Benefits of using cellular phones in learning mathematics}

The participants highlighted the following aspects as characterizing the benefits of learning mathematics with cellular phones (in addition to the aspects mentioned for both of the devices): (1) collaborating in solving mathematical problems in the classroom, by working together, usually in pairs using the same phone, and from distance, by sending SMS and MMS messages to each other in order to solve difficult mathematical problems, and (2) learning anytime and not just in the lesson time.

\section{Benefits of using applets in learning mathematics}

The participants highlighted the following aspects as characterizing the benefits of learning mathematics with applets (in addition to the aspects mentioned for both of the devices): (1) working with software which has a wide interface, and (2) the possibility of learning various mathematical topics and subjects with applets.

\section{Place and time of using cellular phones or applets in learning mathematics}

Some participants said they would use both cellular phones and applets when learning mathematics in the classroom and when solving their mathematical tasks at home, while others said they would use applets in the classroom and cellular phones at home. There were some students who said that they would use cellular phones anytime they solve 'hard' mathematical problems to collaborate on solving such problems.

Those who said they would use cellular phones in the classroom gave reasons like "We can study using cellular phones in our own classroom and not in the computer lab where there aren't enough computers for all of us", "sometimes we don't have internet in the computer lab, and so we can't use applets to study mathematics at school”.

Those who said they would use applets rather than cellular phones in the classroom gave reasons like "The applet's interface is bigger than the cellular phone's interface", "I used my father's cellular phone at home, but I don't have one of my own to bring to the school". Those who said they wouldn't use applets when learning mathematics at home gave a similar reason: "sometimes we don't have internet at home”.

Some participants thought that we shouldn't use applets and cellular phones in the mathematics class all the time because this may endanger the functionality of the teacher in the classroom, for example one participant said: "If we use cellular phones whenever we study math in the classroom the mobile will replace the teacher".

\section{E. Using cellular phones or applets in learning mathematics in the future}

All the participants emphasized that they would use cellular phones and applets in the future. Some of them perceived both of the devices as not appropriate for recognizing the mathematical subject, but as devices with which they solve mathematical problems after they are introduced to the mathematical subject, and with which they do their homework at home. Other participants said that both of the devices can be used in the classroom to learn difficult mathematical topics which are otherwise difficult to grasp, for example one student said: "If I don't understand what the teacher taught I can use the mobile to help me overcome this difficulty". Others perceived both of the devices as devices which add fun or competition to learning mathematics: "we can use the devices once a week to change the atmosphere in the mathematics lesson and have some fun".

Some participants, when talking about their future use of cellular phones in learning mathematics, emphasized that they would use it for collaborating on solving hard mathematical problems, by sending SMS and MMS messages to each other, no matter where or when they do that.

The participants justified their future use of applets and cellular phones in learning mathematics by mentioning the following reasons:

1. The novelty of this kind of learning.

2. The relevance of the learning device to the age in which we live, which is an electronic and digital age.

3. How much one finds learning with or without the device enjoyable, for example one of the participants said: "Learning mathematics without applets is dry and boring".

In the case of cellular phones, they also pointed at:

1. The availability, in terms of place, of cellular phones: "With cellular phones I can study mathematics anywhere”.

2. The collaborative aspect of learning mathematics with cellular phones: "If we want to solve a mathematical problem together from distance, cellular phones help us do so by sending SMS and MMS messages to each other with the beginning of a possible solution or suggestions for a solution”.

Some students suggested adding supplements for the cellular phone in order to use it: "I would use the cellular but with some supplements, for example an amplifier for its monitor. This will enable me to see well, because the cellular then will have clearer images. Imagine that I solve mathematical tasks with the cellular, cool”.

\section{F. The difference between using the cellular phone or the web applet in learning mathematics}

The participants identified eight issues which differentiate between cellular phones and applets in leaning mathematics:

1. The interface size of the computer program with which the user works.

2. The availability of the device.

3. The portability of the device.

4. The easiness of carrying the device. 
5. The availability of mathematical computer programs which suit the device.

6. The distance collaborative aspect of the device.

7. The usability aspect of the device: the easiness and speed with which the user works with the device.

8. The size of the device.

\section{G. Causes given for preferring one of the devices}

When asked about the device that they prefer to use for learning mathematics, some participants used one or more of the previously described eight issues, used to distinguish one of the devices from the other, to argue why they prefer one device over the other. For example, one participant preferred learning mathematics with applets because he has sight problems, so applets which have a bigger interface enable him to learn mathematics more easily.

Some participants emphasized that the devices are similar, but preferred one over the other for one of its aspects, for example one of the participants said: "there is no big difference between the devices, but the cellular accompanies me everywhere and all the time, so I prefer using it”.

Other participants described the difficulty of choosing between the devices: "It's difficult to decide. From one side the mobile is available to everyone, but, from the other side, applets deal with more mathematical subjects”. Some participants looked at the similar aspects of both of the devices to say that they don't prefer any one of them, for example one participant said: "For me, both of the devices help to solve mathematical problems easily. I would use both of them". One participant talked about applets as being portable as the cellular phone: "For me there is no big difference between the devices. I have a laptop with internet, which I bring with me to the school, so both of the devices accompany me all the time. Why should I prefer one of them over the other?”

Eight of the fifteen participants preferred the cellular phone over applets as a device to learn mathematics with, three participants preferred applets over the cellular phone and four said the devices were similar.

\section{DISCUSSION}

When talking about the benefits of learning mathematics with cellular phones and applets, the participants realized a wide variety of similarities and differences between these couple of devices. This can be explained by the participants' familiarity with the internet and the cellular phone environment, though they didn't have any previous experience learning mathematics with web applets or cellular phones. The participants' mentioning of the common benefits of the devices and the special benefits of each one imply that the devices enriched their mathematical learning. This also shows that students living in this electronic and digital age can work with novel mathematical educational devices and benefit from them.

To decide where and when to use cellular phones and web applets in the mathematics classroom, the participants looked at the following aspects: the availability of the device, the infrastructure on which the device depends, the distance collaborative aspect of the device, and the size of the device's interface. I discuss below each one of these factors.

The availability of the device:

Though many researchers mentioned the popularity of cellular phones, among school students' too (Look for example at [16]), cellular phones aren't yet available to all, and part of schools still lack internet or large enough computer labs. These conditions may hinder or make difficult learning with cellular phones or web applets.

\section{The collaborative aspect of the device:}

When mentioning the collaborative aspect of the cellular phone, the participants emphasized two issues: collaborating to solve difficult mathematical problems and collaborating from distance. This means that the cellular learning environment answered some of the learning needs of the students, which are communicating to learn, collaborating to learn and the need to collaborate anytime and everywhere. It seems that the participants didn't experience the collaboration, using the cellular phones, on 'easy' mathematical problems, or that they didn't value such collaboration as when collaborating to solve 'hard' mathematical problems. This emphasis on collaboration to solve 'hard' mathematical problems agrees with the claim of [17] that mobile learning will be adopted by students and teachers depending on how efficient and necessary they consider their services and features.

The screen size of the device:

The small screen size of mobile devices has been mentioned by past researches (for example [18]) as a factor that limits these devices for learning. The participants in this research too mentioned the size of the cellular phone as limiting in certain cases its use as educational device. Though the size of the cellular phone screen is now far better that in the past, nevertheless it's still smaller than the computer screen. The future of cellular phone screen is to become bigger, for it is designated for video and augmented reality applications. What push towards this trend too are the growing educational applications using cellular phones. This means that cellular phones will be used in the future more and more in educational settings.

Deciding about using the cellular phone and web applets in the future, the participants mentioned different reasons which reflect different perceptions of the devices: (1) the cellular phone's ability to be a device for collaboration from distance on hard mathematical problems (2) the devices' potential to be used to practice newly learned mathematical materials (3) the devices' potential to facilitate grasping the hard mathematical material and thus they are worth learning with when the student has a problem with understanding mathematics (4) both of the devices are innovative and thus add fun or different flavor or competition to the traditional setting of the classroom.

To argue why they would use cellular phones and web applets in the future or not, the participants considered the affective aspects of the devices, like encouraging the learning of mathematics, or their novelty and enjoyment aspects, or the devices additional or extra aspects, like the ability of the user to carry them easily anywhere or like the collaborative aspect.

Describing the differences between the devices, the participants perceived different aspects of the devices as 
devices for learning mathematics: the size of the device. The participants talked about the small size of the cellular phone as a positive and negative aspect: It's positive because it allows them to carry the cellular phone anywhere and all the time, which makes the learning with the device possible whenever and wherever they decide to do that, while it's negative because it doesn't allow a wide midlet's interface, which may make the learning with the device somehow difficult. So the participants connected the size of the device with its easiness of portability and its difficulty to present an interface which is clear or obvious. When talking about the size aspect they preferred the cellular phone because it's (1) portable (2) easier to carry than other mobile devices like the laptop, while they preferred the web applets, because, having a wider interface, they have clearer images, which makes working with them easier. This effect of the screen size agrees with other findings in the literature, for example [19] who say that the small size of the screen limits the use of PDAs in certain scenarios. Another aspect which the participants talked about is the availability aspect. Here, what interested the participants are three types of availability: (1) physical availability: the student should own a suitable cellular phone in order to learn with it, or there should be internet in the school computer lab or the student house in order to learn mathematics with applets. (2) place and time availability: because of its small size, the cellular phone is likely to be available wherever the learner goes and it accompanies her all the time; on the condition that she owns it. The use of the Internet is widespread in numerous fields and domains and such is the access to it, but still it's not available in every household or it still suffers from disconnections, in schools or households, from time to time. (3) mathematical software availability: the participants mentioned that web applets deal with more mathematical topics than cellular phone midlets.

When the participants used the availability aspect to decide between the cellular phone and the web applets when coming to learn mathematics, they preferred the cellular phone for its wider physical and place/ time availability, while they preferred the web applets for their wider mathematical software availability.

A different aspect which the participants mentioned, when comparing between the cellular phone and web applets, is the distance collaborative aspect, where the cellular built-in facilities and the mathematical software options enable collaboration when learning a mathematical topic. The participants found these facilities and options practical and helpful, because they enabled them to send SMS and MMS messages to consult each other about the solution of hard mathematical problems, so some of them preferred it for this property.

The last aspect that the participants used to decide between the devices is the usability of working with the device because of its ease of use and speed of input. It seems that the participants' greater acquaintance with the cellular made them feel that working with the midlets is easier and faster than working with the applets. Another possible reason for this claim could be because of the physical actions involved with working with every one of the devices: working with the midlets of the cellular phone involves working with only the keys of the cellular phone, while working with the web applets involves using the key board and the mouse and alternating between them.
Few students preferred the web applets over the cellular phone. This situation could be explained by [20]'s words about this age's students: "they prefer devices that are convenient and comfortable and fit their mobile lifestyle”.

\section{CONCLUSIONS}

The participants perceived varied characteristics of both of the devices. They perceived their general characteristics that make them appropriate for learning mathematics in general, as enabling visualization of the mathematical phenomenon or problem, and their special characteristics that make them appropriate for learning mathematics in special occasions, as collaborating, using the cellular phone, to solve hard mathematical problems. These special characteristics may hinder or encourage the use of the devices for learning mathematics, as the relatively small screen of the cellular phone which hinders its use by students who have sight problems. This perception of the characteristics of the devices and the participants' willingness to use them in the future enable us to conclude that middle school students are ready to learn mathematics with new technologies like the cellular phone and web applets, and from the other side, these devices possess the potentialities that make them efficient devices for learning mathematics in the classroom and outside it. These devices may need improvements or additions, but starting teaching and learning with them would benefit students' learning, from one side, and from the other side, would encourage improving them.

\section{RECOMMENDATIONS}

The participants in this research were middle school students who volunteered to study mathematics outside their schools using cellular phones and web applets. Cellular phones and web applets could be used in whole class contexts too. The use of cellular phones in whole class' contexts may overcome the problems of availability of up-to-date computers. Furthering this research could be done by examining the perceptions of school students regarding learning mathematics with cellular phones in whole class contexts. Another important issue regarding perceptions is the students' perceptions regarding mathematics itself when they work in cellular phones environment.

\section{REFERENCES}

[1] Fildes, J. (2006). Mobiles still ringing in New Year [Online]. Retrieved November 23, 2007, from http://news.bbc.co.uk/1/hi/technology/6199293.stm.

[2] Chen J. \& Kinshuk (2005). Mobile Technology in Educational Services. Journal of Educational Multimedia andHypermedia, 14 (1), 91-109. http://infosys.massey.ac.nz/ kinshuk/papers/jemh2005_mobile_se rvices.pdf.

[3] Rismark, M., Sølvberg, A. M., Strømme, A., and Hokstad, L. M. (2007). Using Cellular phones to Prepare for University Lectures: Student's Experiences. The Turkish Online Journal of Educational Technology, 6(4). http://www.tojet.net/articles/649.htm.

[4] Cobcroft, R., Towers, S., Smith, J. and Bruns, A. (2006). Mobile learning in review: Opportunities and challenges for learners, teachers, and institutions. In Proceedings Online Learning and Teaching (OLT) Conference 2006, pp. 21-30, Queensland University of Technology, Brisbane. https://olt.qut.edu.au/udf/OLT2006/gen/static/papers/Cobcroft_OL T2006_paper.pdf. 
[5] Eason, R., \& Heath, G. (2004). Paintbrush of discovery: Using JAVA applets to enhance mathematics education. PRIMUS, XIV(1), 79-95. (doi:10.1080/10511970408984078)

[6] Martínez-Santaolalla, M.J; Bienvenida, B.F; Túnez, R. S. (2005). ICT In Mathematics Education: Geometry Problem Solving With Applets, Recent Research Developments In Learning Technologies, Department Of Languages And Computation, University of Almería, La Cañada De San Urbano.

[7] Daher, W. (2006). Analyzing and evaluating electronic texts. Unpublished dissertation. Haifa University.

[8] Yerushalmy, M. and Ben-Zaken, O. (2004). Cellular phones in Education: the Case of Mathematics. The Institute for Alternatives in Education, University of Haifa. http://construct.haifa.ac.il/ mi chalyr/celular\%20report.pdf.

[9] Botzer, G. \& Yerushalmy, M. (2007) Mobile Applications for Mobile Learning. In "Proceedings for "Cognition \& Exploratory Learning in Digital Age" (CELDA), Algrave, Portugal.

[10] Sharples, M., Taylor, J., and Vavoula, G. (2005) Towards a Theory of Mobile Learning. Proceedings of mLearn 2005 Conference, Cape Town. http://www.mlearn.org.za/CD/papers/Sh arples-\%20Theory\%20of\%20Mobile.pdf.

[11] Taylor, J., Sharples, M., O'Malley, C., Vavoula, G., \& Waycott, J. (2006). Towards a Task Model for Mobile Learning: a Dialectical Approach. International Journal of Learning Technology, 2(2/3), pp. 138-158. http://www.eee.bham.ac.uk/sharplem/Papers/Task \%20Model.pdf. (doi:10.1504/IJLT.2006.010616)

[12] Pettit, J. and Kukulska-Hulme, A. (2007). Going with the grain: Mobile devices in practice. Australasian Journal of Educational Technology, 23(1), 17-33. http://www.ascilite.org.au/ajet/ajet23/ pettit.html.

[13] Vinci, M. L. and Cucchi, D. (2007). Possibilities of application of e-devices in education: mobile learning. International conference for ICT for Language Learning. Florence, Italy. http://www.leonardo-lets.net/ict/common/download/MariaLuisaVi nci.pdf.

[14] Chance, B., Ben-Zvi, D., Garfield, J., Medina, E. (2007). The Role of Technology in Improving Student Learning of Statistics. Technology Innovations in Statistics Education, 1 (1). http://repositories.cdlib.org/cgi/viewcontent.cgi?article=1004\&con text=uclastat/cts/tise.
[15] Strauss, A., \& Corbin, J., 1998, Basics of qualitative research. Thousands Oaks, CA: Sage Publications.

[16] Holzinger, A., Nischelwitzer, A. \& Meisenberger, M. (2005), Cellular phones as a Challenge for m-Learning: Examples for Mobile Interactive Learning Objects (MILOs). Proceedings of: Third IEEE International Conference on Pervasive Computing and Communication, Kauai Island (HI), 307-311. http://dmt.fhjoanneum.at/kd3/objects/application_pdf/percom_2004_\%20hawa ii_PerIL_ah_nis.pdf.

[17] Corbeil J. R. and Valdes-Corbeil, M. E. (2007). Are You Ready for Mobile Learning? Educause Quarterly, $30 \quad$ (2). http://connect.educause.edu/library/abstract/AreYouReadyforMob ile/40029.

[18] Roberts, J., Beke, N., Janzen, K., Mercer, D., \& Soetaert, E. (2003). Harvesting Fragments of Time: Mobile learning pilot project. Final Report. McGraw-Hill Mobile Learning Pilot Project Consortium, Toronto, Canada. http://www.mcgrawhill.ca/college /mlearning/mlearn report.pdf.

[19] Rawlinson, D. R. and Bartel, K. (2006). Implementing Wireless PDA Technology in the IT Curriculum. EDUCAUSE Quarterly Magazine, 29 (1), http://connect.educause.edu/library/abstract/Imp lementingWireless/39964.

[20] Rishi, R. (2007). Always Connected, But Hard to Reach. EDUCAUSE Quarterly Magazine, 30 (2).

\section{SITES}

[1] Yerushalmy, M. Katriel, H. Sternberg, B. (2001), Visual Math: Functions, http://www.cet.ac.il/math/function/english.

[2] Yerushalmy, M. Weizman, A. and Shavit, Z. (2006), Math4Mobile, http://www.math4mobile.com

\section{AUTHOR}

W. Daher is with the Mathematics Department, AlQasemi College of Education, Baka, Israel (e-mail: wdaher@macam.ac.il).

Manuscript received 09 October 2008. Published as submitted by the author. 